See discussions, stats, and author profiles for this publication at: https://www.researchgate.net/publication/224761317

\title{
Test Bench Realization and Application of Specific Working Cycles for the Characterization of Wheelchair Electrical Drives
}

Conference Paper · August 2006

DOI: 10.1109/ISIE.2006.295912· Source: IEEE Xplore

CITATIONS

7

5 authors, including:

Antonino Oscar Di Tommaso

Università degli Studi di Palermo

104 PUBLICATIONS 901 CITATIONS

SEE PROFILE

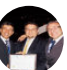

Rosario Miceli

Università degli Studi di Palermo

237 PUBLICATIONS 2,359 CITATIONS

SEE PROFILE

Some of the authors of this publication are also working on these related projects:

DE.DU.ENER.T. View project

wireless power transmission View project
READS

61

6 Diego La Cascia

Università degli Studi di Palermo

65 PUBLICATIONS 561 CITATIONS

SEE PROFILE 


\title{
Test Bench Realization and Application of Specific Working Cycles for the Characterization of Wheelchair Electrical Drives
}

\author{
V. Cecconi, V. Di Dio, A. O. Di Tommaso, D. La Cascia, R. Miceli Member IEEE \\ Dept. of Electrical, Electronic and Telecommunication Engineering, University of Palermo \\ Viale delle Scienze 90128 Palermo, Italy - Tel. +39091 6615285 Fax +39 091488452 \\ cecconi@diepa.unipa.it,vdidio@diepa.unipa.it,ditommaso@diepa.unipa.it, diego.lacascia@diepa.unipa.it, miceli@diepa.unipa.it
}

\begin{abstract}
The life quality of motion disabled people is increased by the use of more and more sophisticated electrical wheelchairs. Despite the diffusion of such aid tools, specific technical standards for the determination of characteristic parameters of their electric drives are not so developed as the ones available for urban electric vehicles. In this paper, in order to define new technical standards for wheelchairs electrical drives, a wheelchair test bench has been purposely carried out. Moreover two specific working cycles, previously conceived and defined by some of the Authors to characterize the performances of the propulsion systems suitable for electrical wheelchair applications, have been here implemented into the test bench and exploited to test an electrical wheelchair. The tests results are particularly suitable to characterize the propulsion drive of the wheelchair.
\end{abstract}

\section{INTRODUCTION}

Recent development of more and more performing and reliable electrical drives in the automobile field has allowed to replace internal combustion engines with electrical drives in many applications. Often electrical drives have not the same performances and autonomy of internal combustion engines but are much more respectful of the environment in which they work. The necessity of the environment respect becomes irreplaceable when the vehicle runs in closed and no ventilated places. For these reasons the use of electrical drives in wheelchairs becomes inalienable. Motion disabled people should be able to move themselves both in domestic ambient and on the road by means of the wheelchair without changing the wheelchair type. Thus the wheelchair must be able to move with its typical movements both in domestic and in pedestrian ambient. Frequent accelerations (positive and negative), many stops, standstill positions in locked condition and also short time intervals at constant speed characterize the wheelchair operations. All this must be done at zero gas emission condition. These short considerations allow to conclude that the performances of a traction electrical drive, suitable for wheelchair applications, need to be verified by using test methods similar to those used for electric vehicles or internal combustion engines [1]. In [2] some of the Authors proposed and implemented in simulation environment two specific working cycles named "pedestrian test cycle" and "domestic test cycle" for the characterization of wheelchair propulsion electrical drives. These working cycles have been here implemented into a test bench purposely carried out and exploited to test a wheelchair electrical traction drive. These working cycles are useful for the selection and design of the drive itself and of its components and also to check out the whole drive in the manufacturing stage as well as in the consistent or final test.

In this paper, in paragraph II. the domestic and pedestrian test cycles are reported, in paragraph III. the chosen wheelchair and the test bench purposely carried out to apply the working cycles are presented, in paragraph IV. the control algorithm used is explained, finally in paragraph V. the experimental results (significant electrical and mechanical quantities) are presented and discussed.

\section{TEST CYCLES}

Electric vehicles dynamic performances depend on their traction drives. With reference to the specific use of a wheelchair particular importance is to be focused on accurate movements and precise positioning in domestic ambient while long lasting autonomy and fast motion are preferred in external pedestrian utilization. The proposed testing approach by steering the wheelchair to perform normalized motion trajectories [2] permits to identify fast and concise indexes about the behavior and the performances of the traction drive as a whole. This necessity arises from the fact that the behavior of the drive cannot be deduced from the set of the single component characteristics. In [2] and [3] some of the Authors outlined the state of art of international standards in this field. Particularly, IEC, ISO and CEN standards have been mentioned. The conceived and developed test cycles [2] reproduce domestic and pedestrian typical working conditions to test electric drives specifically designed for wheelchair applications. Figs. 1 and 2 show the trajectories of the motor angular speed versus time defined in the aforesaid working cycles whose peculiarities are explained in [2]. The characterization of the electric drive for the wheelchair may be 


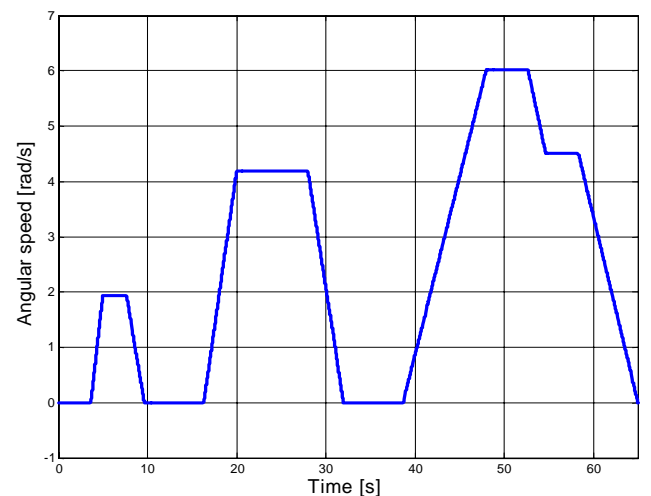

Fig. 1. Pedestrian test cycle.

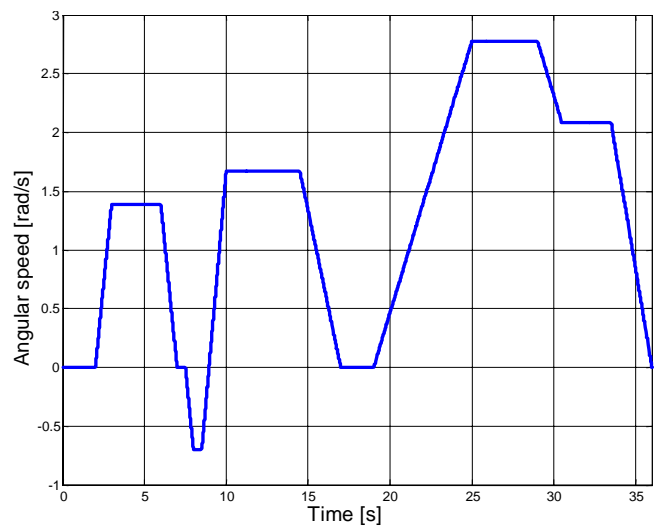

Fig. 2. Domestic test cycle.

obtained following the working cycles under appropriate load, inertial mass, and passive friction. The tests carried out by applying both the domestic and pedestrian test cycles allow the measurement of peculiar quantities for the electrical drive characterization [4]. In particular, motor angular speed, motor supply voltages and phase currents, dc supply current and voltage, instantaneous power and energy consumption can be measured or calculated. The tests can be carried out taking into account different loads and/or road slopes the vehicle should overcome by using a mechanical brake applied to the wheelchair. Moreover the working cycles can be used to analyze and compare different electrical drive control algorithms and/or different types of energy suppliers like fuel cell, super capacitors, etc.

\section{WHEELCHAIR AND TEST BENCH}

To apply the above mentioned working cycles to an electric wheelchair in order to evaluate the wheelchair electric drive performances a specific wheelchair has been utilized [5] and a suitable test bench has been set up. The chosen wheelchair is a MEYRA $^{\circledR}$ Sprint GT with a mass of $110 \mathrm{~kg}$. It has been modified equipping it with two axial flux PM synchronous motors each of one mounted inside a wheel (Fig 3). Figs 4 and 5 show respectively the two PM wheel motors and their cross section. The two PM brushless motors have: $140 \mathrm{rpm}$ rated speed, $14 \mathrm{Nm}$ rated torque, $84 \mathrm{Nm}$ peak torque, $10.8 \mathrm{~A}$ rated current, 65 A peak current, $205 \mathrm{~W}$ rated power, 16 rotor poles,
$7.4 \mathrm{~kg}$ weight, $86 \%$ efficiency, $0.063 \mathrm{~V} / \mathrm{rpm}$ b.em.f. The motor parameters are: $\mathrm{R}=0.112 \Omega, \mathrm{Ld}=1.1 \mathrm{mH}, \mathrm{Lq}=1.03 \mathrm{mH}$, $\lambda_{\mathrm{PM}}=0.167 \mathrm{~Wb}$. Each motor is equipped with a coaxially mounted position transducer (12 bit absolute encoder). Two three-phase current regulated PWM (CRPWM) inverters, whose hysteresis bands have been fixed at about $3-4 \%$ of the rated motor current, supply the two motors (see Fig. 6). The primary energy source consists of a storage system composed by two lead acid accumulators, each of one has $12 \mathrm{~V}$ rated voltage and $45 \mathrm{Ah}$ rated charge. The two accumulators are connected in series. The test bench, purposely conceived and in Fig. 7 shown in a schematic block diagram with the wheel chair electric drive, consists of a dSPACE ${ }^{\circledR}$ (digital Signal Processing And Control Engineering) control system, a Yokogawa DL 1740 oscilloscope with the relative current and voltage sensors and a brake system.

The dSPACE $^{\circledR}$ system controls the electric drive which is loaded with a brake. By means of the aforesaid sensors connected both to the oscilloscope and to the $\operatorname{dSPACE}^{\circledR}$ the chosen electrical and mechanical values are measured. In particular, the dSPACE ${ }^{\circledR}$ is a control system, based on floating point microprocessors, that permits the implementation, verification and real-time simulation of algorithms even somewhat complex; the control system here used is based on the DS1103 board which is equipped with two processors: a master Power PC 604e and a Texas Instruments slave DSP of the type TMS320F240, characterized by cycle frequencies respectively of 400 and $80 \mathrm{MHz}$.

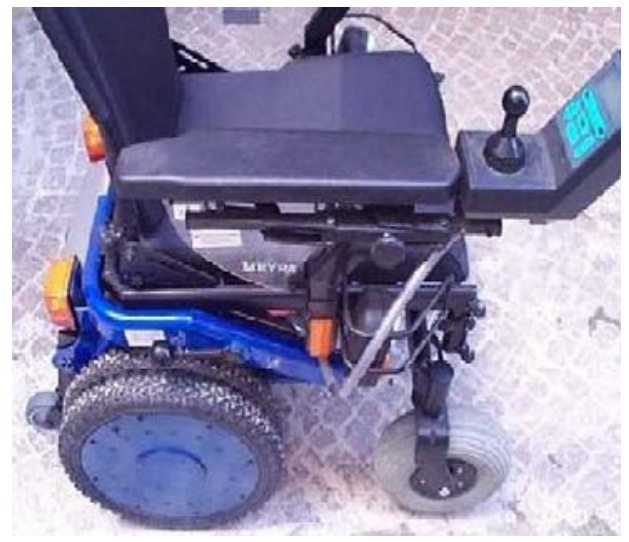

Fig. 3. Modified wheelchair.

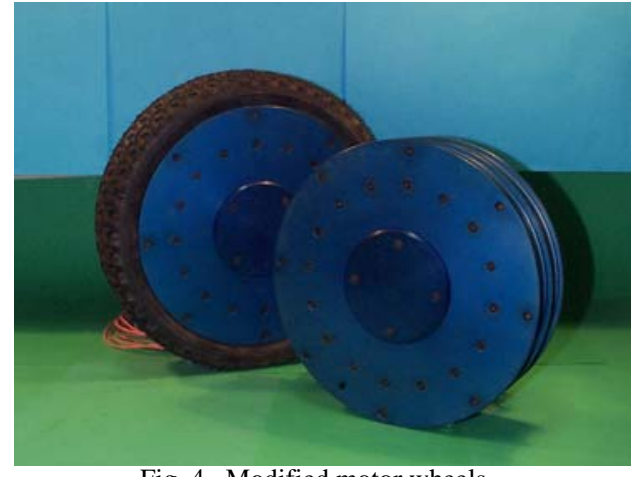

Fig. 4. Modified motor wheels. 


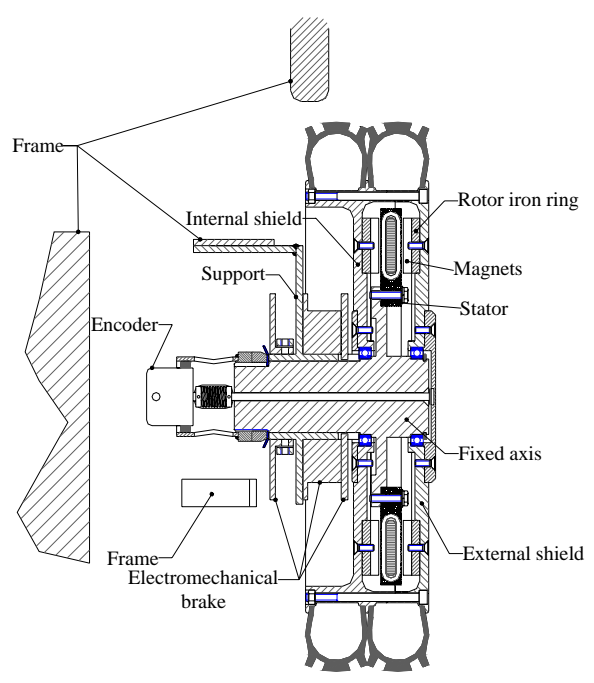

Fig. 5. Motor cross section.

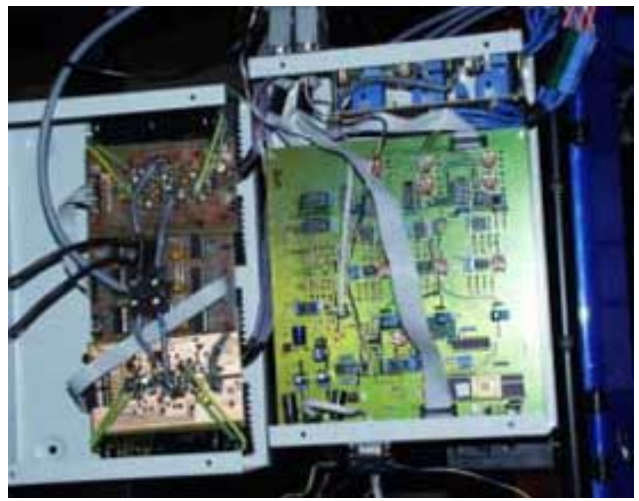

Fig. 6. Electronic power converters (left) and current loop control board (right) mounted on the wheelchair.

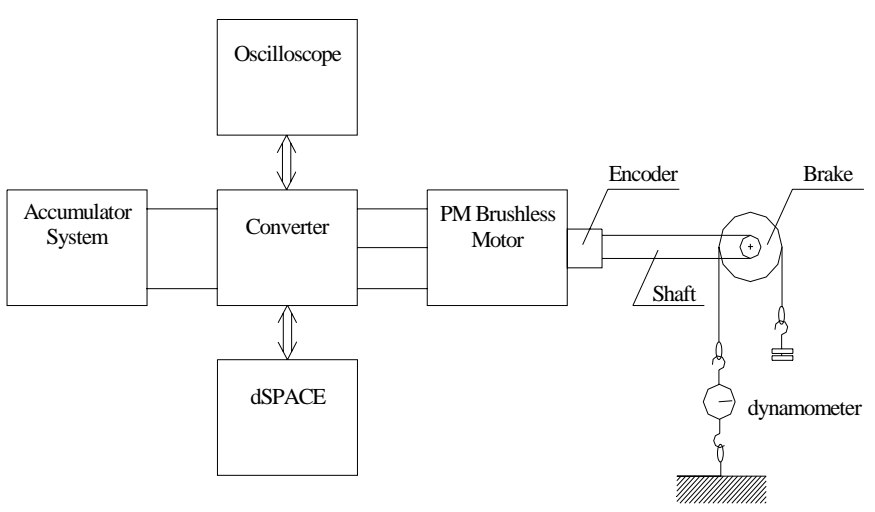

Fig. 7. Wheelchair and test bench schematic block diagram

The board has 8 analogue input channels (four 16 bit A/D converters and four 12 bit ones), eight output analogue channels (with 12 bit $\mathrm{D} / \mathrm{As}$ ), six incremental encoder channels and a series of timers and digital I/O ports. The oscilloscope is a YOKOGAWA DL 1740 oscilloscope, four acquisition channels and spectra analyzer with $500 \mathrm{MHz}$ bandwidth. To load the PM motor a mechanical friction belt-pulley brake purposely assembled to measure the motor torque, by means of a precise dynamometer, was used. To execute the needed measurements in order to characterize the wheelchair drive a speed control algorithm has been implemented on the dSPACE ${ }^{\circledR}$.

\section{CONTROL Algorithm}

The control algorithm used to implement the working cycles on the test bench is based on a PI speed controller with a speed limiter and an anti wind-up system. The speed controller output is the quadrature axis current component $i_{q}$ whereas the direct axis current component $i_{d}$ is kept to zero according to the brushless motor drive adopted control strategy [2], [6]. These two quantities $\left(i_{d}\right.$ and $i_{q}$ ) are fed to the CRPWM board (see Fig. 6) where, knowing the exact position of the rotor by means of the absolute encoder, are then transformed in threephase current reference signals in order to drive the current regulated modulator. The feedback speed signal used to close the speed control loop is derived from the absolute encoder output. The current control loop is entirely performed on the CRPWM control board while the speed one is implemented on the dSPACE $^{\circledR}$. The block diagram of the wheelchair speed control system is shown in Fig. 8. The working cycles reported in the previous paragraph are used as speed references for the control system. The selection of the two cycle types can be easily made on-line thanks to the presence in the control system of a software based multiport switch. The speed references (working cycles) and the feedback signals are sent to the digital speed regulator. By means of several trial and error attempts, the $K_{p}$ and $K_{i}$ PI regulator gains have been settled up to 0,1 and 0,8 respectively. The signal coming out from the wheelchair control algorithm is the current reference (or torque one) fed to the CRPWM inverter control board mounted on the wheelchair.

\section{EXPERIMENTAL RESULTS}

Many tests and measurements to choose the most suitable electrical drive components and to set up their parameters have been carried out for both the cases of the pedestrian cycle and the domestic one which are reported in Figs. 1 and 2 respectively. The tests have been executed on one of the two motors. The tests on the wheelchair electrical drive have been performed in many working conditions and with different energy suppliers. All these tests have been carried out to determine the characteristic parameters and the performances of the drive. The measured speed versus time allows, by comparing it with the motor reference speed, to outline the dynamic performances of the drive. Are also taken into account the supply voltage, the DC supply current, the motor phase current and the motor line voltage.

The first two electric quantities permit to analyze and characterize the accumulator system, the second ones the motor behavior. Finally, the energy consumption during a working cycle can be calculated and this gives information about the wheelchair autonomy.

The experimental results are presented and discussed in the following sections. 


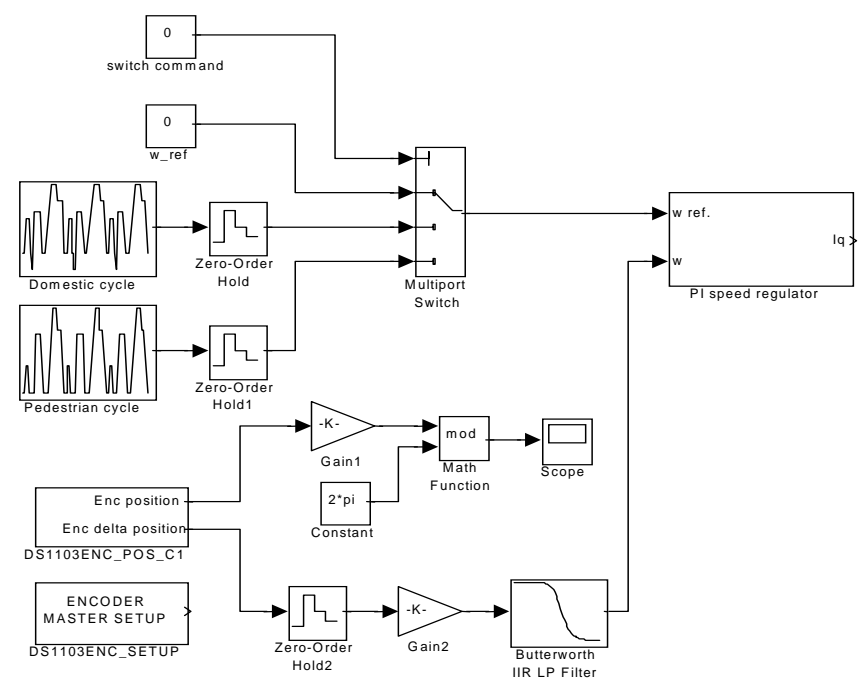

Fig. 8. Wheelchair control algorithm block diagram.

\section{A. Pedestrian Cycle Experimental Results}

Here the results of one test performed with the motor reference speed shown in Fig. 1 are reported. In Fig. 9 the motor reference speed is reported together with the measured one. The reference speed is tracked quite exactly and this proves that the control algorithm carried out makes the electrical drive to be an optimal dynamic performances one. In Figs 10, 11, 12 and 13 the wheelchair electrical drive supply voltage, the DC supply current, the motor phase current and the motor line voltage are reported when the wheelchair electrical drive is supplied by a $24 \mathrm{~V}$ electrical accumulator system and the mechanical brake is applied. It may be noticed that the current supplied by the accumulators results quite smooth thanks to the capacitors chosen in parallel connection with the accumulator system. Moreover the supply voltage is quite constant because the accumulator system is well designed with respect to the electric drive requested performances. In addition Figs. 12 and 13 show that chosen axial flux PM synchronous motor allows the wheelchair to respect perfectly the steered working cycle. By using the measurements shown in Figs. 10 and 11 the energy consumption from the electrical accumulator system has been calculated and it is shown in Fig. 14. Therefore, the test cycle permits to characterize the energy consumption of the accumulator system during a cycle. By repeating several times the test cycle and measuring how many cycles the wheelchair is able to run before the supply system on board exhaustion it is also possible to take information about the wheelchair autonomy.

\section{B. Domestic Cycle Experimental Results}

Here the results of one test performed with the motor reference speed shown in Fig. 2 are reported. Figs. from 15 to 20 show the same quantities as before. The reference speed is tracked quite exactly which means that the electrical drive has optimal dynamic performances in this case too. The supply voltage, the DC supply current, the motor phase current and the motor line voltage characterize the good behavior of the electric drive steered by the domestic test cycle. Finally, the energy consumption calculated (see Fig. 20) allow to characterize the wheelchair autonomy in the domestic ambient.

\section{CONCLUSIONS}

In this paper, in order to define new technical standards for wheelchairs electrical drives, a wheelchair test bench has been purposely carried out. Two specific working cycles have been here implemented into the test bench and exploited to test an electrical wheelchair. In particular, many tests and measurements to choose the most suitable electrical drive components and to set up their parameters have been executed for both the cases of pedestrian and domestic cycle. The results obtained from the application of the two working cycles allow the optimization of the drive components and to experience the effects of different loads, typical road slopes and parameter variations while the wheelchair is working. Moreover test results are particularly suitable to characterize the propulsion drive of the wheelchair by analyzing the supply voltage, the DC supply current, the motor phase current and the motor line voltage. Thanks to these measurements it is also possible to estimate the energy consumption of the wheelchair during a working cycle and in many working conditions.

The wheelchair test bench and the working cycles are also useful for the EMI (Electro Magnetic Interference) characterization of the drive, for the improvement of the EMI performances during the designing stage and to carry out the compliance tests. Finally, the wheelchair test bench is easily automatizable allowing to automatically realize characterization procedures based on the two working cycles.

\section{ACKNOWLEDGEMENTS}

This work was realized with the contribution of MIUR, MAP, CRUI and ICE. All sections have been equally and jointly developed by the authors.

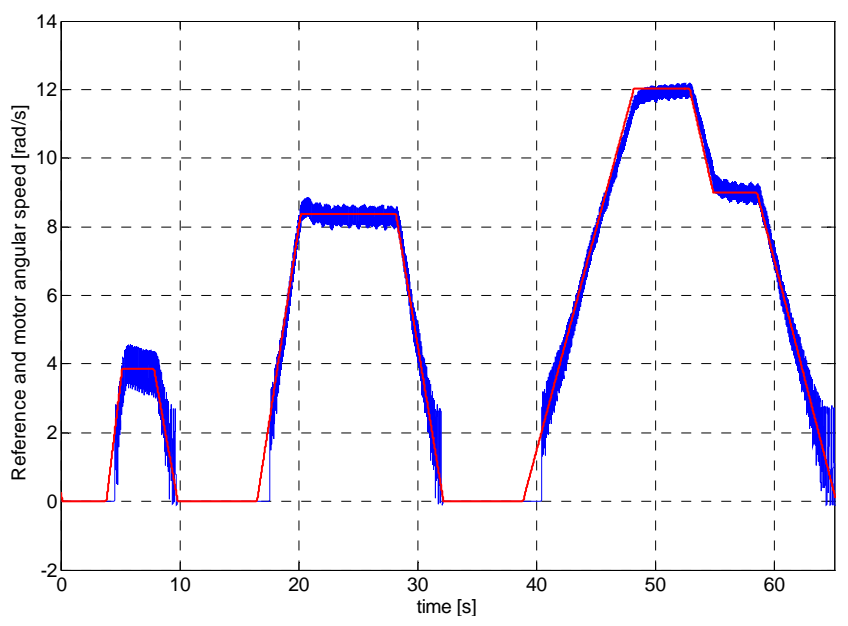

Fig. 9. Reference and motor speed during the pedestrian cycle tests. 


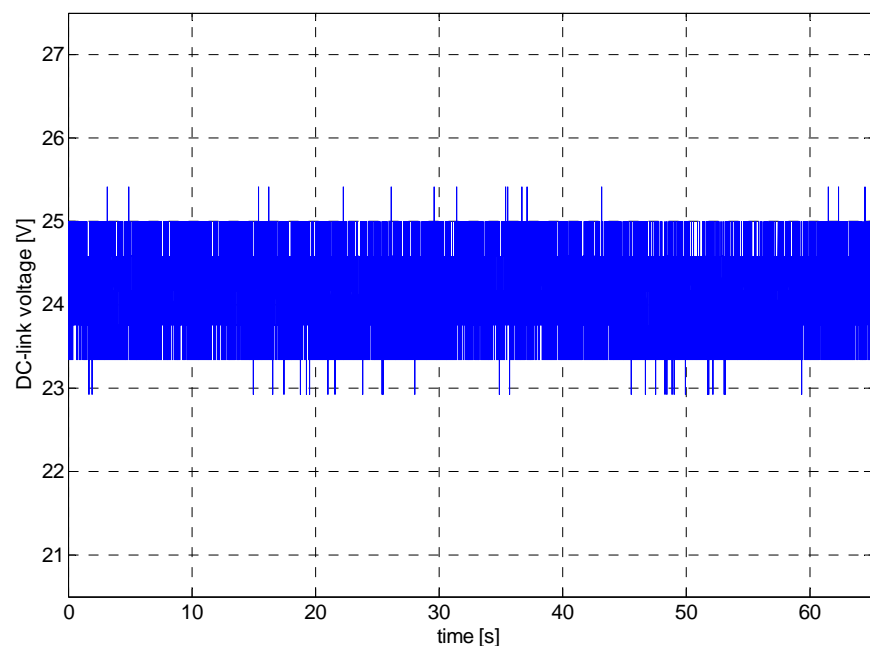

Fig. 10. Supply voltage during the pedestrian cycle tests when the wheelchair electrical drive is supplied by a $24 \mathrm{~V}$ electrical accumulators system and the mechanical brake is applied.

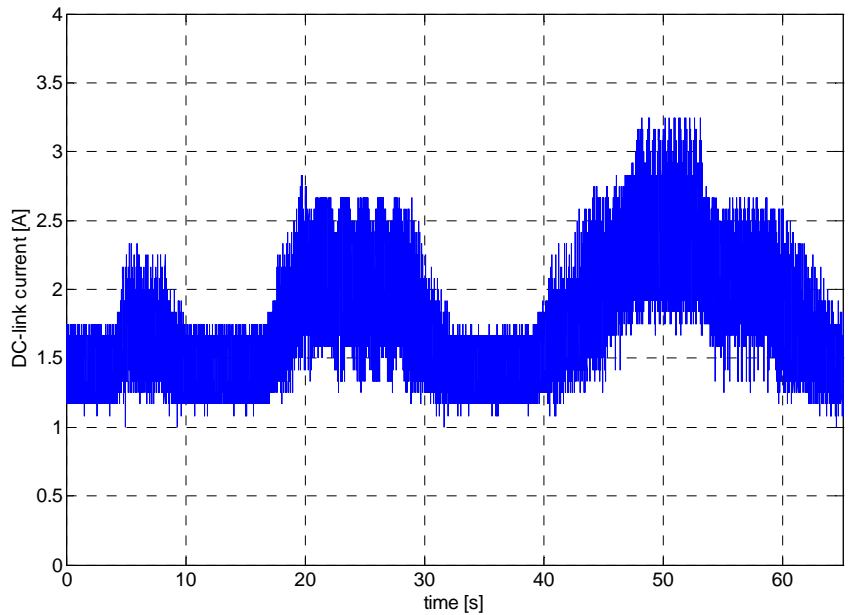

Fig. 11. DC supply current during the pedestrian cycle tests when the wheelchair electrical drive is supplied by a $24 \mathrm{~V}$ electrical accumulators system and the mechanical brake is applied.

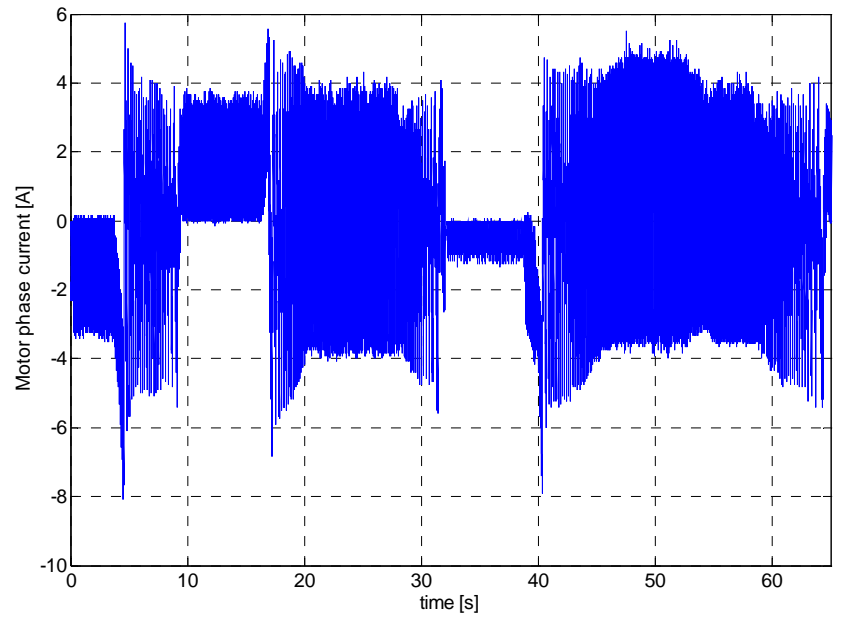

Fig. 12. Motor phase current during the pedestrian cycle tests when the wheelchair electrical drive is supplied by a $24 \mathrm{~V}$ electrical accumulators system and the mechanical brake is applied.

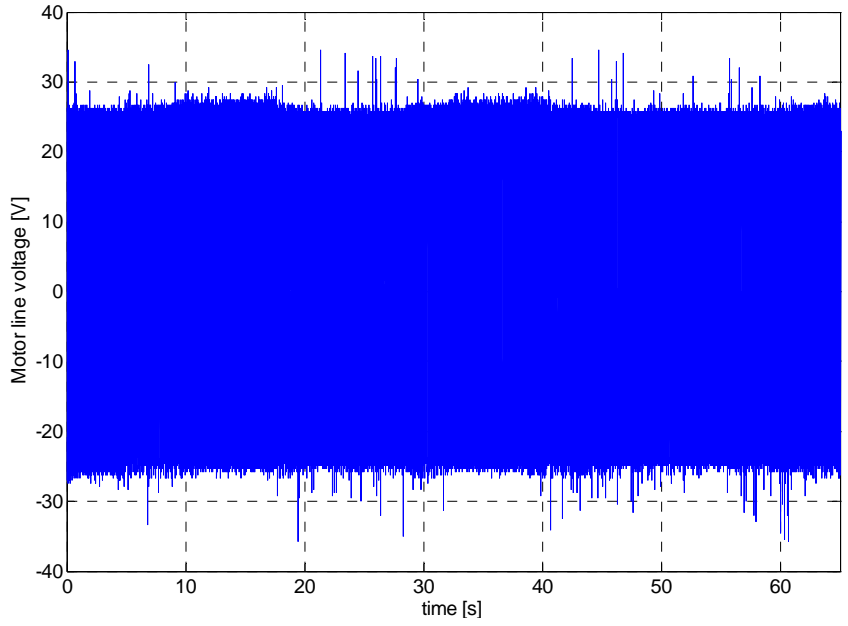

Fig. 13. Motor line voltage during the pedestrian cycle tests when the wheelchair electrical drive is supplied by a $24 \mathrm{~V}$ electrical accumulators system and the mechanical brake is applied.

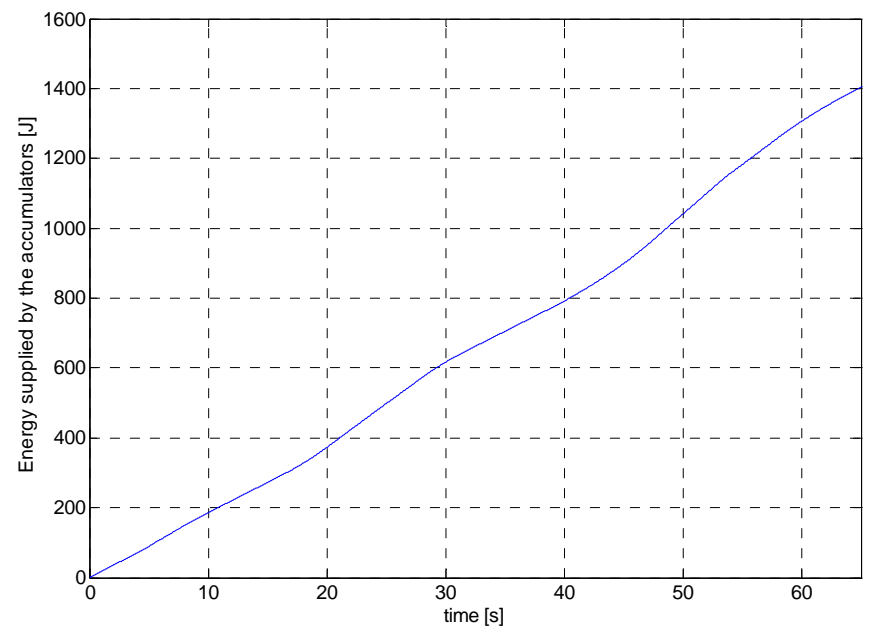

Fig. 14. Energy consumption during the pedestrian cycle.

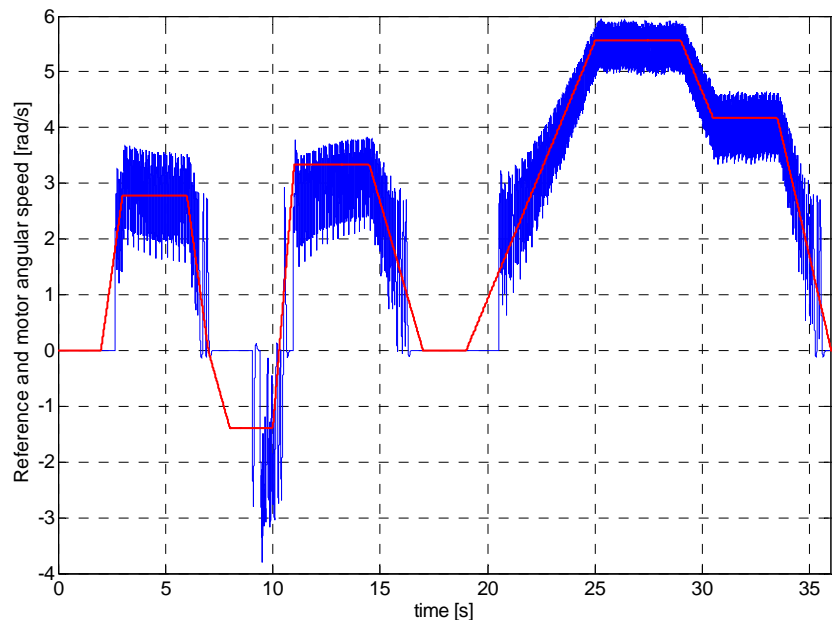

Fig. 15. Reference and motor speeds during the domestic cycle test. 


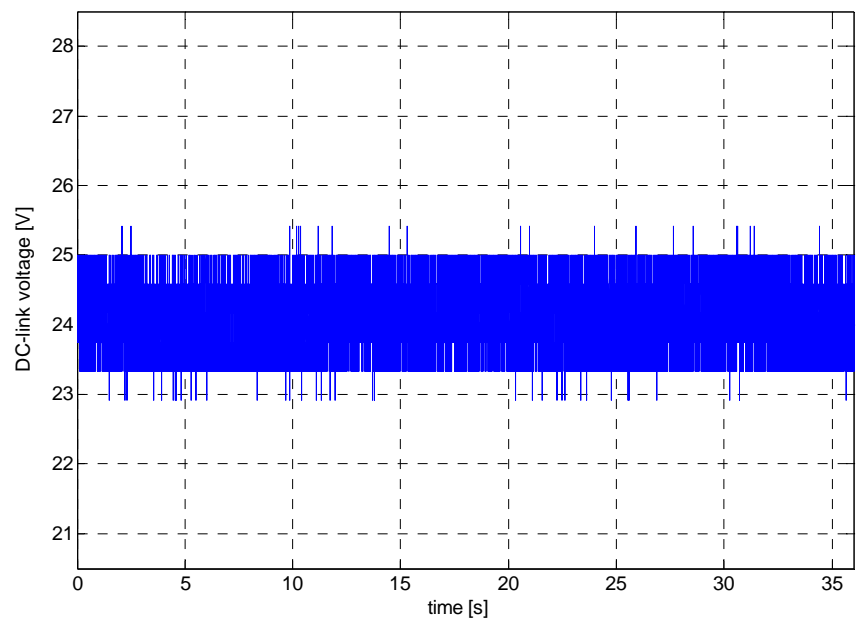

Fig. 16. Supply voltage during the domestic cycle tests when the wheelchair electrical drive is supplied by a $24 \mathrm{~V}$ electrical accumulators system and the mechanical brake is applied.

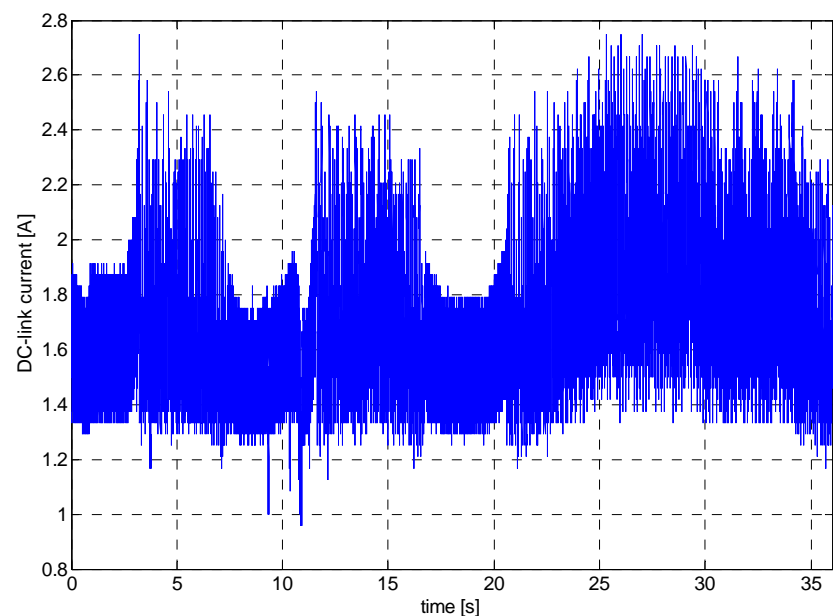

Fig. 17. DC supply current during the domestic cycle tests when the wheelchair electrical drive is supplied by a $24 \mathrm{~V}$ electrical accumulators system and the mechanical brake is applied.

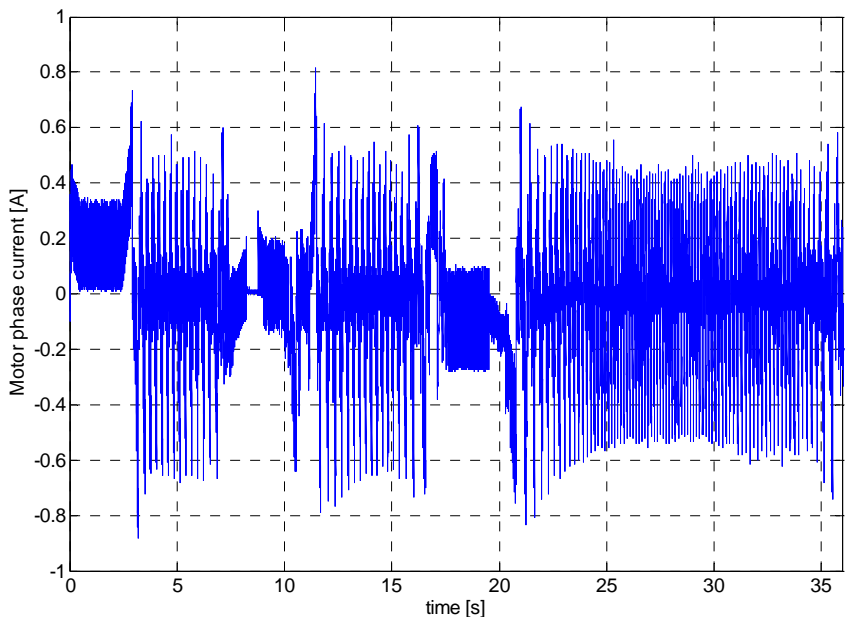

Fig. 18. Motor phase current during the domestic cycle tests when the wheelchair electrical drive is supplied by a $24 \mathrm{~V}$ electrical accumulators system and the mechanical brake is applied.

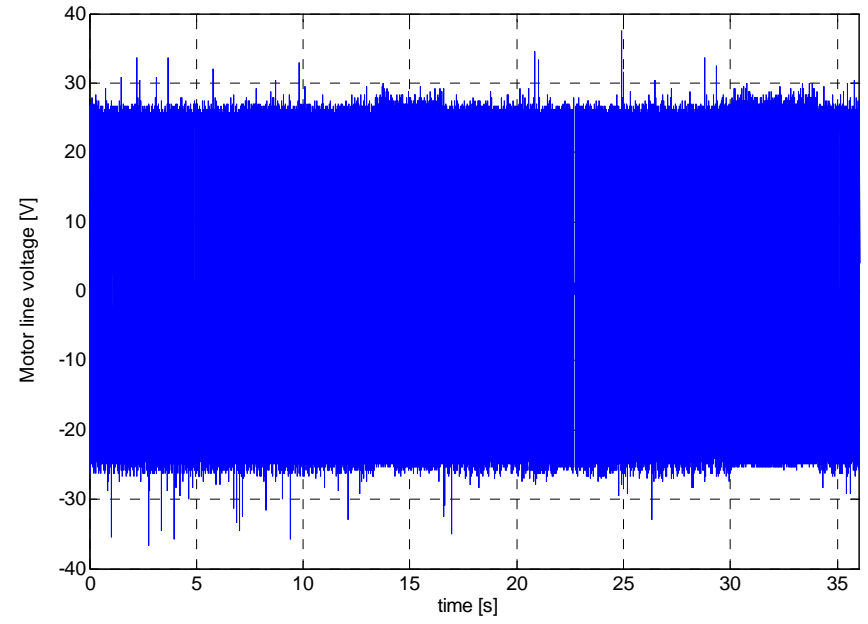

Fig. 19. Motor line voltage during the domestic cycle tests when the wheelchair electrical drive is supplied by a $24 \mathrm{~V}$ electrical accumulators system and the electromechanical brake is applied.

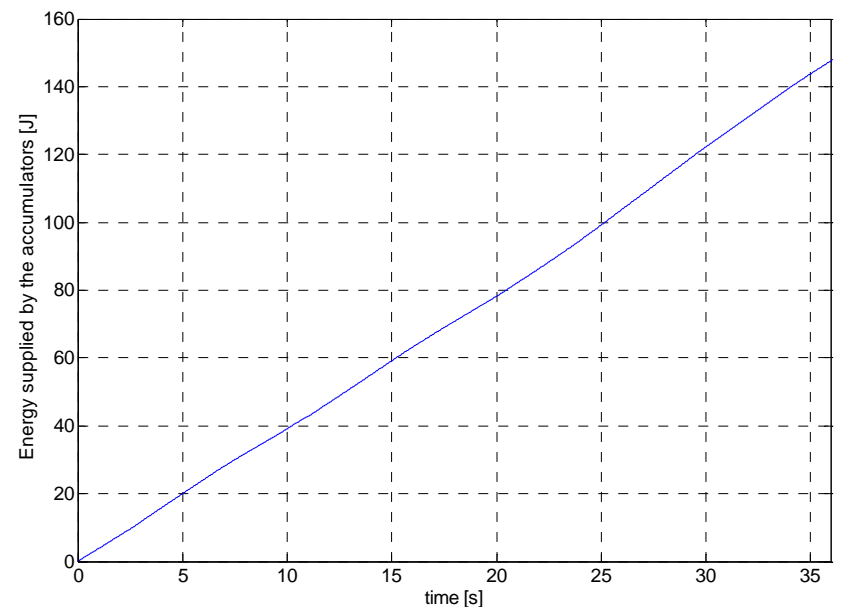

Fig. 20. Energy consumption during the domestic cycle.

\section{REFERENCES}

[1] L. Gazzella, A. Amstutz, "CAE Tools for Quasi-Static Modeling and Optimization of Hybrid Powertrains", IEEE Transactions on Vehicular Technology, Vol. 48, no. 6, November 1999, pp. 1762-1769.

[2] V. Di Dio, A.O. Di Tommaso, R. Miceli, C. Cavallaro, A. Raciti: "Test cycles for the characterization of electrical drives devoted to wheelchair applications”, Proceedings of the Fourth IEEE International Caracas Conference on Devices, Circuits and Systems, Aruba, 17-19 April 2002, Page(s):P021-1 - P021-6.

[3] R. Miceli, M. Montana, G. Ricco Galluzzo, R. Rizzo, G. Vitale, “A Test Cycle for the Standardization and Characterization of Electric Driver for Electric Vehicles - Experimental Approach”. PEDES'96, New Delhi, 12 January, 1996, Vol. 1, pp. 313-317.

[4] E. Basilico, S. Nuccio, M. Speciale, G. Vitale, "Individualization of characteristic parameters of an electrical drive and realization of a suitable automatic test system". 1st European Conference on Reliability, Standardization and Certification of Industrial Electric Drives, Milano, Italy, 25-27 May, 1992.

[5] A. Di Napoli, F. Caricchi, F. Crescimbini, L. Solero: "Innovative permanent magnet motor drive for wheelchairs", International Conference on Electrical Machines 2002, 25-28 Agosto 2002, BruggeBelgio.

[6] A Consoli, A. Raciti, B. Dobrucky, V. Hrabovcova, "Static and Dynamic Behaviour of Disk Synchronous Motors". Proceedings of the IEEE International Symposium on Industrial Electronics ISIE'93, Budapest, Hungary, 1-3 June, 1993, pp. 646-651. 